\title{
DE LA AMNISTÍA MIGRATORIA AL DEVENIR MIGRANTE. \\ EL IMPASSE DE LA CIUDADANÍA EN EL CONTEXTO DE LA FEMINIZACIÓN DE LA MIGRACIÓN EN CHILE.
}

Patricio Azócar

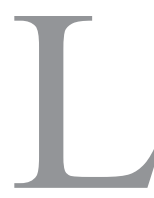

os estudios sociales de los Últimos 27 años en el País han descrito la incorporación efectiva de Chile en los procesos migratorios globales como un proceso movilizado principalmente por factores económicos, los cuales a nivel situado señalan como protagonistas en su mayoría a mujeres procedentes de un eje de circulación geo-territorial sur-sur. Estos diagnósticos, no obstante, se tornan estrechos para abordar las complejizaciones políticas que ha significado la experiencia migratoria en sus capilaridades, el cual ha permitido precipitar un impasse que ha sabido poner en entredicho los sistemas referenciales tradicionales de la ciudadanía y el derecho moderno. En este contexto propongo una reflexión crítica que permita indagar en las tramas micro-políticas que constituyen lo que se ha denominado como feminización de las migraciones en el marco de las luchas por la ciudadanía, tornando visible las articulaciones gubernamentales con que la discusión política local se incardina con un régimen global de desplazamiento de poblaciones, asumiendo como artefactos referenciales de traducción de este espacio g-local dos enunciados de lucha y reivindicación de derechos políticos y sociales propiciados por los movimientos migrantes en el país: la amnistía migratoria y la campaña "Todas somos migrantes" del Colectivo de Mujeres Migrantes Warmipura.

Palabras clave: Feminismo, migración, trans-nacionalidad, trans-frontera, nomadismo. 


\section{Migraciones Contemporáneas}

Las migraciones contemporáneas son un fenómeno de alta complejidad social, cultural, política y económica a través del cual las sociedades neoliberales se contraen y se emplazan a sí mismas a interrogar sus modos de sentir y vivir el presente histórico. De alguna forma, las condiciones con que las migraciones se nos tornan presente, desde las frías cifras, las imágenes más generales con que los medios de comunicación las grafican a nivel internacional hasta los con-tactos más estrechos con las polifonías y policromías corporales en nuestros territorios locales son las mismas a través de las cuales el contexto histórico se nos torna sensible y, con ello, los límites a través de los cuales tratamos de nombrarle, de referenciarle y referenciarnos en él; los marcos normativos y los sustratos imaginales con los cuales le aprehendemos y nos aprehendemos en él.

Para el pensamiento, desde el que surge imprevisto en la cornisa barrial hasta el que se amasa en las academias universitarias, las migraciones contemporáneas se han convertido en una grilla de inteligibilidad que nos abre paso al mundo, o sea, a los modos con que lo producimos, lo habitamos, lo afirmamos, tensamos, transamos, tramamos, pensamos, valoramos, sentimos, significamos y expresamos. Y donde no solo en términos retóricos es que se habilitarán brechas a las fronteras con que delimitábamos las relaciones sociales en función de específicos regímenes de identificación, reconocimiento y percepción, sino que en términos materiales es que nos empujarán a dialogar, discutir, problematizar y reinventar las semióticas con que nos relacionamos con las y los otros, con las figuras humanas y no-humanas asociadas a la extrañeza, a la diferencia radical, a la infamiliaridad. Como señalara Hanna Aren$\mathrm{dt}$, a la exigencia política y responsable que a nivel general nos cabe con la novedad ${ }^{1}$.

En Chile las migraciones contemporáneas, en cuanto novedad, tienen diversos modos de expresión que transitan desde las capilaridades sociales y las experiencias más inconfesables en las calles, en los trabajos, en las escuelas, a los que se confeccionan al nivel de las tecnologías sociales como los medios de comunicación, los discursos científicos o las máquinas de representación política. Específicamente para el caso de esta reflexión, propondré un pliegue intersticial y eminentemente político para

1 ARENDT, H. "The Crisis in Education", en Between Past and Future (1959). Londres: Penguin Books, 1977. 
abordar lo que será entendido como migraciones contemporáneas y que nos remitirá a los bordes ético-políticos que torna sensible la vivencia de la migración a través de los enunciados de lucha con que los movimientos de migrantes han disputado los marcos de reconocimiento en el país y han expuesto los modos de su presencia entre la experiencia vivida de la migración y los marcos de representación con el que se les norma y condiciona su reconocimiento, tanto en clave jurídico-normativa como al nivel de las marcas sociales y culturales — racializadas y generizadas - con el que se les aprehende en el país.

Si nos adentramos en las cifras de esta nueva migración transnacional contemporánea podemos rastrearla desde los últimos 30 años de migración internacional extranjera hacia Chile, identificando una tendencia que la señala en aumento desde 83 mil personas en 1982 a 411 mil en $2014^{2}$. Solo dentro de la primera década posterior a la dictadura, entre 1992 y el 2002, el crecimiento de poblaciones de extranjeros de países vecinos, como la peruana, se incrementó en un $400 \%{ }^{3}$. De acuerdo a estas cifras, se advierte que entre el 2002 y el 2014 América del Sur se consolida como la región desde donde proceden las principales poblaciones migrantes que llegan a Chile estimándose que sus trayectorias obedecen al efecto de las restricciones fronterizas en el eje norte del globo ocurridas posterior al 11 de septiembre del 2001. Esa tendencia ha ido profundizándose desde el año 2005, en el que los flujos a nivel intrarregional representaban el $67,7 \%$ de la migración internacional en el país ${ }^{4}$ y de los cuales el INDH estima se llegó al 72\% para el año 2010).

Durante la última década las migraciones en Chile se tornan cada vez más diversas, incrementándose y fortaleciéndose comunidades como la boliviana, que crece desde el 2002 al 2014 de un 4,6\% a un 21\%; la colombiana, que sube de un 3,4\% a un $16 \%$; la española, que tiende desde el 2005 de un $1,9 \%$ a un 5,0\%. En la misma línea, los últimos años señalan la apertura de una discontinuidad con respecto a los ejes de circulación y las tendencias de la primera década, destacando comunidades como la haitiana y la dominicana, que crecen de un $0 \%$ a un $2 \%$ y de un $0,2 \%$ a un $3 \%$ respectivamente. Esta discontinuidad, aunque se torne patente durante los últimos 5

2 Anuario (Departamento de Extranjería y Migración). Migración en Chile 2005-2014.

3 STEFONI, C. "Inmigrantes transnacionales: La Formación de comunidades y la transformación en ciudadanos" (Capítulo 9). FLACSO, sede Chile.

4 Anuario..., Op.Cit., 2005-2014. 
años de acuerdo a investigaciones del Observatorio iberoamericano sobre movilidad humana (2016), conservan una tendencia que se desarrolla durante toda la primera década del 2000 y que evidencia una fuerte presencia migratoria femenina, indígena $\mathrm{y}$, más recientemente, afrodescendiente ${ }^{5}$.

En el análisis de las migraciones económicas y transnacionales, en términos estadísticos, toma centralidad el fenómeno de la feminización de las migraciones con que los estudios de la primera década del 2000 lo denominaron, señalando a través del censo del 2002 que, de una cantidad de 184.464 personas extranjeras en el país, el $52 \%$ aproximadamente eran mujeres ${ }^{6}$. De esta cifra, solo en la comunidad peruana, que representa la mayor cantidad de migrantes residentes en el país, superando las 125.000 personas, las mujeres representan para el año 2011 el $60,2 \%$ del total ${ }^{7}$. De acuerdo con lo anterior, podríamos anexar que durante el malogrado intento de censo del año 2012, las cifras generales de población migrante indican que la tendencia sigue en incremento, duplicando la cantidad a 339.536 personas de las cuales se infiere que se mantiene un mayor porcentaje de mujeres con respecto a hombres. De acuerdo a las últimas cifras, de un total de 411.000 migrantes en Chile el 52, 6\% seguirá siendo de mujeres ${ }^{8}$.

Las migraciones contemporáneas a las que hago referencia emergen como concepto en la década de los noventa en pleno proceso de reorganización social y política de los estados transicionales posdictadura a nivel latinoamericano. De acuerdo a lo revisado, estarán caracterizadas como procesos principalmente inmigratorios, compuestos en su mayoría por mujeres procedentes de un eje de circulación transnacional y geo-territorial sur-sur que tanto a comienzos de los noventa como en la primera década de los dos mil, se estima promovido por razones eminentemente económicas y laborales. Estas irán definiendo a Chile como un país de destino de estos nuevos flujos de poblaciones migrantes en la medida que también le será reconocido como

5 OBDMI - La migración en Chile: breve reporte y caracterización, Instituto Universitario de estudios sobre Migraciones, Madrid, España, 2016.

6 INE - Instituto Nacional de Estadística. Datos extraídos el 20 de julio de 2015 en www.ine.cl/filenews/ files/2011/enero/pdf/enfoque_extranjeros.pdf, 2015.

7 INDH - Instituto Nacional de..., Op.Cit., 2011.

8 OBDMI - La migración...,Op.Cit., 2016. 
un país que aseguraría condiciones estables e idóneas para quienes deciden migrar ${ }^{9}$. Ahora, si bien las migraciones contemporáneas emergen como un fenómeno social feminizado, eminentemente económico que acusa la estabilidad como factor determinante de su trayectoria, tienen como procedencia una serie de antecedentes de extrema violencia, arbitrariedad, discrecionalidad y excepcionalidad estatal, los cuales desembocaron en procesos de alta emigración, persecución y desnacionalización de sus propios ciudadanos bajo la rúbrica de los discursos de seguridad nacional. Marco jurídico-normativo que se preserva hasta la actualidad en la ley de 1975 y que prepara las condiciones para altos procesos de fluctuación y desplazamientos masivos en el contexto de guerra fría, pero a su vez en su reversibilidad, en el proceso de neoliberalización de las formas de vida a nivel global.

Frente a este contexto migratorio tremendamente ambivalente, es que la propuesta de situar las reivindicaciones de las luchas por la amnistía migratoria y la campaña del colectivo de mujeres migrantes "Todas somos migrantes" como operadores analíticos y estratégicos de las migraciones contemporáneas pretende realizar una interpelación a los efectos de verdad y los marcos de reconocimiento con que la matriz de seguridad interior del estado se preserva bajo una retórica hospitalaria e inclusiva en el nuevo contexto de la migración posdictadura. Refiriéndome con esto específicamente a las tecnologías de gobierno con que se operacionaliza acumulativamente la contradicción inclusivista-excluyente que, a pesar de las readecuaciones de los marcos jurídicos de extranjería y migración en Chile que se han realizado durante estos 26 años de transición, sigue funcionando como una tecnología de subjetivación "bicéfala" o anfibológica — declarativamente humanista, al mismo tiempo, que efectivamente seguritaria - idónea al nuevo contexto global de precarización, de hostilidad general, de dispersión espacial que es , paradójicamente, de integración global ${ }^{10}$ ¿A qué nuevas codificaciones de la política y sus marcos nos remite la lucha por la Amnistía migratoria en el contexto chileno? ¿Cuáles son los devenires y desafíos que plantea la enunciación de las mujeres y las territorialidades corporales de la campaña "Todas Somos migrantes" a estas nuevas semióticas del reconocimiento?

9 STEFONI, C. Inmigrantes..., Op.Cit., 2004.

10 SASSEN, S, Contrageografias de la globalización. Género y ciudadanía en los circuitos transfronterizos. Traficantes de sueños, Madrid, 2003. 


\section{De LA AMNistía}

La migración contemporánea podría ser figurada con la recurrida imagen del iceberg, donde las cifras solo alcanzan a señalar una estimación probable, vuelta coherente solo en la medida de una exigencia gubernamental-seguritaria de previsión y control de las poblaciones. En su reverso: situaciones de entrada no autorizada o ingreso irregular y de vencimiento, caducidad o cualquier otra forma de carencia de una visa o permiso de residencia ${ }^{11}$. Correlato gris, cifra negra que, pese a ser estimada en cifras no puede ser nunca reducida y definida por parcialidades, todo lo contrario, queda renuente como un exceso en torno al cual se alimentan procesos de politización y despolitización, convirtiéndose en pieza clave de la comprensión de la temática migratoria y de las construcciones discursivas con las cuales adquirirá materialidad y presencia en el contexto chileno.

En torno al exceso que supone la cifra negra es que tanto en la década de los noventa (1998) y los dos mil (2007) el tema de las migraciones intensificó su politización mediante la puesta en discusión y en disputa de las formas y los usos con los que se invoca y figura esa parte que no forma parte de lo visible de las migraciones: "los irregulares". Parte Sin Parte que permitió interrogar los marcos con los cuales se delimita y señala a los migrantes en el contexto actual, sea como pre-texto reificante de cierto goce identitario basado en una narrativa perversa de la nación; como variable "contribucionista", condicionado su reconocimiento a la ley de producción de valor y acumulación a través de la cual se incorpora en la medida que se plusvaloriza su diferencia $\mathrm{o}$, un tercer espacio, como posibilidad de una trama narrativa posnacional de reconocibilidad, parafraseando a Arendt, donde lo común bien pueda estar incondicionada a cualquier tipo de pertenencia previa o familiaridad cultural. Pese a uno $\mathrm{u}$ otro, es que en torno a la extrañeza de lo que no se sabe y las figuras de la amenaza con que se les aprehende es que las retóricas del presente permitirán tornar sensible los sentidos y las nuevas normativas con las que se mira al otro y se condiciona o no su presencia en el territorio.

Tanto en 1998 como en el 2007 la amnistía migratoria fue propuesta por las organizaciones de migrantes como un proceso urgente y necesario. Por cierto, lo indicarán como un proceso "indispensable" frente a las condiciones particularmente críticas

11 NORIEGA, R, Sobre la amnistía migratoria, parte III. En Revista Sur, 2014. 
a las que se ven expuestos todas y todos los migrantes en el país, especialmente los irregulares, y que diagnostican como producto de una situación de crisis y desborde de los aparatos administrativos encargados de regularizar a las y los migrantes, como en el caso del Departamento de Extranjería y migración. Diagnóstico, sin embargo, que no pretende aislar excepcionalmente el caso como si fuera una falla técnica del sistema, sino constatar que de raíz está determinada por la insuficiencia de los soportes institucionales normativos y burocráticos que la producen, refiriéndose a la ley de 1975, y con la que se preserva un desfase con la realidad migratoria actual impulsando la misma irregularidad como efecto propio de la norma en cuestión ${ }^{12}$. Considerando lo anterior, el argumento en torno a la amnistía migratoria como tal no la justifica como una herramienta que exista por fuera del marco normativo efectivo, todo lo contrario, la identifica como constitutiva de la propia condición jurídica excepcional con que se produce la irregularidad, proponiéndola como utensilio legal a disposición del mismo estado de urgencia, de exposición a la violencia, que promueve la propia ineficacia de la norma jurídica. Como dirá Noriega ${ }^{13}$ :

\footnotetext{
"las Amnistías Migratorias son consecuencias necesarias dadas por la existencia de la "lógica de las migraciones clandestinas", para nuestro parecer las Amnistías Migratorias son consecuencia necesaria de los marcos normativos que generan la misma irregularidad".
}

De acuerdo con el argumento, la amnistía migratoria no solo es coherente con el espíritu de la ley, sino que reafirma la condición excepcional de la ley para garantizar su ejercicio pleno que, para el caso de las y los migrantes irregulares, queda a disposición como una herramienta estratégica que permite aproximar al migrante y al Estado benefactor para propiciar una respuesta conjunta a la irregularidad, que en cuanto tal, es representada en su multidimensionalidad como un "factor pernicioso tanto para la sociedad como para el extranjero que se encuentra en tal condición ${ }^{14}$. Dicha respuesta se reivindica siempre en función de los niveles de maximización de la precariedad con la que la insuficiencia de la norma, el Estado en su negligencia, vulnera a las y los migrantes, pero a su vez, cómo esa vulneración porta potencial-

12 NORIEGA, R. Sobre..., Op.Cit., 2014.

13 NORIEGA, R. Sobre..., Op.Cit., 2014.

14 NORIEGA, R. Sobre..., Op.Cit., 2014. 
mente niveles de daño que amenazan al Estado al ser propiciadoras de prácticas de riesgo e inseguridad en la misma sociedad.

En estos términos, la amnistía supone una negociación que permitirá invocar la excepcionalidad de la ley en función del restablecimiento de un diálogo quebrado, suspendido por la insuficiencia de la ley y que, en este caso, supone la normalización de una forma del derecho al que ya no le es consustancial la protección ni la garantización social, sino que la producción de formas de vida altamente precarizadas. Por el contrario, excepcionalidad estatal que desmanteló el mismo espíritu que la amnistía pretende invocar, el de la protección, garantización y el derecho político, por medio de la normalización de la excepción durante el ejercicio de desnacionalización/ desgarantización que imprimió el Estado chileno contra ciudadanos nacionales y extranjeros durante la dictadura en la misma ley de extranjería y migración.

Paradoja que postula a la amnistía con una potencia inaudita, la de invocar desde la excepcionalidad de la ley un espíritu desmantelado y excluido del paradigma de la misma ley para tornar posible un lenguaje de protección y garantía social dentro de un marco donde no tiene cabida como tal, en cuanto yace saturado por un discurso del riesgo, la amenaza y la peligrosidad que al anterior indirectamente tiende a inhibir.

Mediante un uso estratégico del imaginario de la seguridad la amnistía pretende volver a situar, mediante la invocación de un poder político capaz de suspender la norma excepcional que funda el principio de ciudadanía pos-dictadura en la era neoliberal, una pregunta (im)posible sobre el derecho que, en cuanto a la pregunta por la posibilidad de un ejercicio de derecho al no-nacional, vuelve a poner sobre la dimensión pública una pregunta política, el de la palabra justicia.

Esta paradoja a la que nos emplaza la lucha por la amnistía migratoria podemos abordarla desde la lectura de Agamben en torno a la dimensión política de las sociedades en clave stasiológica, o sea desde una teoría de la guerra civil. Teoría que nos premune de los elementos analíticos para comprender, como señalará el italiano, el estado de indistinción actual entre guerra y paz, entre la esfera pública y la privada, arriesgando sumar la de regular e irregular, en un contexto caracterizado por el agotamiento de una concepción de la política y de la guerra basada en el derecho público como sustrato meta-político de protección, y la consolidación de una 
norma excepcional, extra-estatal señalará Sassen, basada en la regla del mercado, el miedo, la inseguridad social y el riesgo como eje operador del nuevo sistema de administración necro/bio político del neoliberalismo. De alguna forma, citando a Agamben, un estado social donde "la stasis constituye un umbral, a través del cual la pertenencia doméstica se politiza en ciudadanía y, inversamente, la ciudadanía se despolitiza en solidaridad familiar. Considerando que las tensiones son, como hemos visto, contemporáneas, se vuelve decisivo el umbral en el que ellas se transforman y se invierten, se unen o desunen".

Siguiendo el mismo análisis respecto a este estado de disipación de las formas tradicionales de la política bajo la imagen de incursiones de politización y despolitización entre las dimensiones privadas y públicas, entre el no-ciudadano y el ciudadano, entre el extranjero interior y la polis, la amnistía, señalará Agamben $^{15}$, sería el comportamiento más conforme a la política en el estado de guerra civil y en la cual el irregular yace abandonado como figura actualizada de nudificación de la vida contemporánea. Comportamiento político en cuanto por medio de la invocación de un poder soberano basado en el "espíritu" de la ley se permitirá restituir su derecho de vida conjurando su posición de exclusión, con que a la vez es incluido en el orden jurídico como irregular, al mismo tiempo que por medio de la politización de su condición de no-ciudadanía permitirá incluirse en el orden jurídico de la ciudad.

De acuerdo con lo anterior, la amnistía migratoria queda como un recurso jurídico estratégico que le queda a quién expuesto a la desnacionalización y desprotección, al abandono, a la guerra total, a la nudificación, siguiendo a Agamben ${ }^{16}$, pretende aún reestablecer los términos de la violencia frente a la cual está expuesto y según ella también dispuesto, por medio de la invocación de un poder mnémico, de un olvido sin resentimientos, capaz de redefinir las tensiones y los daños acontecidos entre ambas partes, entre el oikos y la polis, entre el extranjero interior (el irregular) y el ciudadano, propiciando la búsqueda de una reconciliación en torno a la condición de ciudadanía de la cual el irregular no era parte en cuanto tal, sino solamente como sin-parte.

La propuesta de Amnistía migratoria, sin embargo, dentro de la lucha de las y los

15 AGAMBEN, G. Homo Sacer II [en línea] extraído en 2016 de https://artilleriainmanente.noblogs.org/ post/2017/01/14/stasis/, 2016.

16 AGAMBEN, G. Homo..., Op.Cit., 2016. 
migrantes sufrió una inflexión importante que multiplicó posiciones en torno a ella. A las organizaciones vinculadas y coordinadas para seguir adelante con el proceso de exigencia les fue necesario preguntarse críticamente por sus propios límites, por los propios marcos en los que se delimitaba la pregunta por la justicia en el desarrollo de la reivindicación de la amnistía, por consiguiente, por los límites de la soberanía y las facultades materiales del Estado y la ciudadanía en el contexto actual.

La regularización migratoria que planteamos es un acto de justicia que posibilitaría el acceso a una visa definitiva con el fin de dar una respuesta a la precarización de nuestras comunidades. Sin embargo, debemos ser claros en que la regularización coyuntural, es un parche que no resuelve el problema estructural (Noriega, 2014)

De alguna forma, los movimientos migrantes toparon con las nuevas demarcaciones de la comunidad política contemporánea y los nuevos regímenes de poder con los cuales la ciudadanía queda deslindada de las viejas formas de soberanía, siendo hoy en día instrumentalizada para producir y fijar poblaciones valorizadas antes que por su protección, por los niveles de desposesión a la que son expuestas y condicionadas a nuevos modos complejos de gobernabilidad que no pueden fácilmente ser reducidas a actos de soberanía ${ }^{17}$. Como señalarán las y los migrantes:

\begin{abstract}
"Cuando se habla de amnistía se hace referencia a la "acción y el resultado de perdonar una pena, ofensa o deuda". En este sentido, ¿de qué ofensa hablamos? cuando el marco legislativo migratorio chileno, pone trabas para que las personas en movilidad accedan a regularizar su situación migratoria, cuando el sistema de visas estimula por sí mismo la irregularidad convirtiéndola en un círculo vicioso. Nos han querido endosar esta injusticia, atribuyéndonos a los propios migrantes una supuesta "irresponsabilidad, un perjuicio" (MAM, 2014)
\end{abstract}

Siguiendo a Judith Butler ${ }^{18}$, los sin-estado, los no-ciudadanos, al ser politizados advierten una transformación en el orden de la gubernamentalidad que indica que la ciudadanía va poco a poco desistiendo de su condición garantista para ir quedando

17 BUTLER, J. Marcos de Guerra. México: Paidós, 2010.

18 BUTLER, J. Marcos..., Op.Cit., 2010: 71. 
solo en su operatoria excepcional, cada vez menos apegada a la semiótica jurídica soberana, por el contrario, cada vez más a una de la norma excepcional. Así se distancia de Agamben, aduciendo que lo que hay no son instancias indiferenciadas de nuda vida sino estados de desposesión altamente judicializados ${ }^{19}$, permitiéndonos repensar las formas del derecho más allá de las figuras soberanas donde se clausura la política moderna, pero a su vez donde aparece el cuerpo como el campo de la politicidad, a su vez, como el territorio donde los nuevos regímenes de gobernabilidad estatal-corporativos garantizan su persistencia en la medida que saturan los cuerpos, a las y los migrantes, neutralizando y atenuando cualquier posibilidad de acción política.

La amnistía, por tanto, es extremada a sus propios límites, señalando las condiciones de posibilidad en las que restringe la acción política de las y los sujetos a la soberanía estatal, advirtiéndose insuficiente para permitirle a las y los sujetos leer las nuevas tramas de poder que componen la idea de regularización y la saturan discursivamente mediante nuevos regímenes normativos que a condición de reconocer al cuerpo "en regla" les impiden poner en cuestión, mapear y afrontar, la unidad de medida, el principio de equivalencia, según el cual es normalizado:
"El trabajo del Movimiento se centra en instalar un pensamiento crítico entre las comunidades, reflexionar con profundidad sobre estos temas, para que las decisiones recaigan directamente en las personas que han tomado conocimiento de la realidad y que responsablemente se hagan cargo de ellas" 20

La pregunta política que emerge en el plano de la inflexión a la dimensión del derecho soberano con el que se invoca la amnistía, pasa por una politización de las comunidades de migrantes y no migrantes, por un desborde de las parcialidades de la ley y por una superación de una noción de ciudadanía condicionada, como señalábamos anteriormente, a sentidos de pertenencia o familiaridades culturales. En este sentido, una politización que no descansa solo en el decisionismo arbitrario y excepcional del Estado soberano sino en la búsqueda incesante de formas posnacionales de articula-

19 BUTLER, J, Marcos..., Op.Cit., 2010, 73.

20 MAM, Movimiento Acción Migrante. Acerca de la amnistía migratoria en Chile [Disponible en web] http://www.revistasur.cl/revistasur.cl/2014/09/acerca-de-la-amnistia-migratoria-en-chile/, 2014. 
ción y convergencia. Parafraseando a Butler, una política performativa que despliegue una noción de poder que incluya y exceda a la vez la cuestión de los derechos del ciudadano en clave estatal-nacional, por lo tanto, en clave soberana, repiense un "nosotros" en términos globales para hacer frente a una política de imposición y active alianzas centradas en la oposición a la violencia estatal y su capacidad para producir, explotar y distribuir diferencialmente precariedad ${ }^{21}$ :

\begin{abstract}
"la apuesta del Movimiento va más allá de la actual coyuntura en defensa de un nuevo proceso de regularización, el desafío es cooperar en la creación de una ley que respete la dignidad de las personas, legitimando ampliamente en la sociedad, tanto chilena como migrante, esta mirada concentrada en la seguridad de las personas, en la inclusión social, en la democracia y participación, como un tema que no le compete soloa1@s migrantes ${ }^{22}$.
\end{abstract}

\title{
Feminización de las Vidas rotas
}

Extremar los límites de la amnistía tornó sensible un nuevo régimen de gobernabilidad que no ejerce poder por fuera de las estructuras de la soberanía, sino que se pliega a la violencia estatal con la cual el derecho es restringido y condicionado a una noción de ciudadanía, que persiste retóricamente sobredeterminada a tramas ficcionales de lo nacional. No obstante, advierte un nuevo marco trans-nacional que impone el principio de equivalencia con el cual los cuerpos son "regularizados" o normalizados a través de tecnologías de subjetivación capitalísticas gestionadas por el mercado y en función de un régimen de acumulación y extracción de valor expandido a nivel global, y donde se redefine la pertenencia a través de nuevas formas del trabajo (trabajo flexibilizado, trabajo precarizado), como del capital (capital financiero, capital inmaterial), como de nuevos mercados (mercado de la seguridad, mercado de remesas, mercado habitacional, mercado doméstico, mercado part-time, mercado comunicacional).

21 Butler en Marcos de Guerra (2010) propondrá la noción de precariedad como aquella que refiere a las condiciones de vida con las cuales socialmente y diferencialmente se maximizan o minimizan los niveles de exposición a la precariedad entre las y los distintos sujetos.

MAM, Movimiento..., Op.Cit., 2014. 
De alguna forma, las colectivas migrantes al interpelar la acción mnémica de la amnistía no como olvido-sin-resentimiento sino como perdón culposo, ponen en evidencia los marcos capitalísticos con los que se actualiza la ciudadanía en clave neoliberal, promoviendo un desglose crítico de la matriz de reconocibilidad que la condiciona verticalmente a una relación intercambiaría organizada en función meramente de los intereses del acreedor: el Estado (nacional)-corporativo. Poder avistar una política posnacional de reconocimiento sostenida en la dignidad de las personas se plantea la necesidad de deconstruir críticamente las relaciones asimétricas con las que se cristaliza el intercambio en una economía de desposesión, deuda y culpabilidad, por lo tanto, de optar por prácticas que tiendan a maximizar las capacidades ética-políticas de participación en la vida pública, antes que desde el condicionamiento a una representación que comporta la medida de tu valorización, desde la experiencia vivida y compartida con otras y otros radicalmente diferentes en un tiempo histórico singular:

"Una comunidad que no dependa de representantes, sino que sea un todo multicéntrico. Ello solo es posible desde la participación transversal, sin imponer agendas o conceptos preestablecidos...no se trata solo de regularizar, de dar una amnistía, de crear otros marcos legislativos, se trata de fomentar la democracia participativa de nuestras comunidades excluidas y que son parte de un Chile en el siglo XXI.”

Identificar la matriz de reconocibilidad de la violencia estatal como lógica de asignación de valor y ciudadanía en función de una lógica de intercambio deudor-acreedor, alerta la necesidad de avistar las dimensiones diferenciales con que a nivel subjetivo ciertos cuerpos son diferencialmente valorizados con respecto a otros y sujetos a una condición de inferioridad, a fuerza de inmovilización. Parafraseando a Butler, tornar sensible e interrumpir los mecanismos síquicos de regulación y control de los sujetos frente a la asimetría con que a nivel global se configuran y constituyen sus relaciones, sus distancias, sus proximidades ${ }^{23}$. Desentrañar las lógicas de superioridad / inferioridad con que se estratificarán las vidas, entre las migrantes y los "nativos", entre las y los migrantes o entre las y los "nativos", pudiendo desmarcarlos de una pedagogía de la crueldad con la cual se tienden a normalizar y acostumbrar los cuerpos a dichas asimetrías.

23 BUTLER, J. Mecanismos psíquicos de poder. España: Cátedra, 2001. 
Siguiendo a Segato, una política en femenino que permitiría desentrañar los marcos diferenciales con que se (en)marcan los cuerpos y se sujetan con fuerza a asimetrías extremadamente violentas, como las del género y la división sexual. De la misma forma, desarticular una economía basada en la intemperie y la desprotección ${ }^{24}$ encargada de producirla y reproducirla en base a un modelo de subjetivación masculina y patriarcal, afín a la guerra, la crueldad y la desposesión por acumulación ${ }^{25}$ donde el cuerpo de las mujeres y otras minoridades, como las disidencias a la heteronormatividad, a través de su aplastamiento vuelven a resolver el pacto de reconciliación de las ciudadanías neoliberales a través de la reificación de una masculinidad puesta en crisis junto con el pacto social del derecho soberano:

Este modelo de masculinidad violenta emparentada con el Estado no es un caso aislado en México, sino de producción y reproducción de ciertos rasgos de género que se repiten en los países ex coloniales y se relaciona con la identidad nacional, creando en palabras de Connell, "un orden de género mundial", el cual puede definirse como "la estructura de relaciones que, a escala mundial, conecta a los regímenes de género de las instituciones con las órdenes de género de las sociedades locales". Este orden de género es el resultado de la sociedad global, la cual distribuye a través de dispositivos culturales y tecnologías de género, unos ideales de aspiraciones tanto de masculinidad como de feminidad, que estandarizan a todo el mundo, ideales que son consumidos por las sociedades g-locales ${ }^{26}$

La invisibilidad y la precarización de las mujeres por las nuevas condiciones de pobreza no solo señalarán sus cuerpos como los cuerpos sacrificiales por excelencia sobre los cuales se constituyen los nuevos marcos normativos del reconocimiento capitalístico sino que también indicarán que la femineidad es menos una propiedad asociada a una determinación biológica, que una construcción socio-cultural dispuesta a suturar la relación de superioridad-inferioridad, deudor-acreedor como condicionante del pacto neoliberal de ciudadanía. De hecho, señalará una condición pasiva frente

24 SEGATO, R. Pedagogía de la crueldad: entrevista a Rita Segato, [disponible en web] http://anarquiacoronada.blogspot.com/2015/05/pedagogia-de-la-crueldad-entrevista.html, 2015

25 SEGATO, R. Pedagogía de..., Op.Cit., 2015.

26 VAlEnCIA, S. Capitalismo Gore. Control económico, violencia y narcopoder. México: Paidós, 2016. 
a la precariedad, tanto a las mujeres, como a los niños y a los jóvenes varones, y en muchos casos, a todos las y los cuerpos que socialmente se les inferioriza y subjetiva como cuerpos expuestos a la violencia, por ejemplo, a las y los migrantes ${ }^{27}$.

En función de lo anterior, los estudios referidos a las matrices simbólicas del reconocimiento del otro en Chile estarán atravesadas por un soporte de género que construirá el sentimiento de pertenencia e identidad nacional, evidenciando estar marcada la ciudadanía por un predominio de lo masculino que dispondrá las figuras de significación social de acuerdo a un imaginario andro-céntrico y heteronormativo. De hecho, se ha acuñado incluso la noción de "andro-identidad" para referirse a la narrativa representacional de lo chileno como a los marcos del reconocimiento con que se feminiza la alteridad en su complejidad.

Parafraseando a Gayle Rubin en "Tráfico de mujeres", y para leer las migraciones contemporáneas y esta redefinición del marco de reconocimiento, la división sexual del trabajo permite acentuar una direccionalidad del deseo en pos de asegurar una relación intercambiaría mediada por el trabajo que, en las actuales condiciones del capitalismo, se vuelca sobre el cuerpo, el deseo, la producción y satisfacción de necesidades asociadas a la construcción mercantil de un modo de vida generizado/ aplastado/atenuado/sobresaturado. Un intercambio que produce y organiza el marco diferencial del derecho en función de un derecho de concesión, no de propiedad, que asumirá el mercado respecto a los cuerpos, y también emplazará a los cuerpos a hacer sobre sí lo mismo, y donde puede funcionar la normalización efectiva o una empresa de fuga insospechada. Una fuga que afirme la potencia de producción de nuevas formas de intercambio, circulación y producción simbólica del deseo, no mediadas por una matriz masculina de violencia y acumulación ${ }^{28}$.

27 SEGATO, R. Antropología y derechos humanos: alteridad y ética en el movimiento de los derechos universales. Brasilia: Serie antropológica, 2004.

28 RUBIN, G. El tráfico de mujeres: notas sobre la "economía política” del sexo. En: Nueva Antropología. Vol. VIII, No 30 , 1986: pp. 95-145. 
Todas somos migrantes. Apuntes no conclusivos en torno a un PROYECTO NOMÁDICO

"El cuerpo como valija y sin frontera geopolítica. Nuestros cuerpos, nuestros territorios" 29

\section{¿podrias decir en qué país nacieron?}

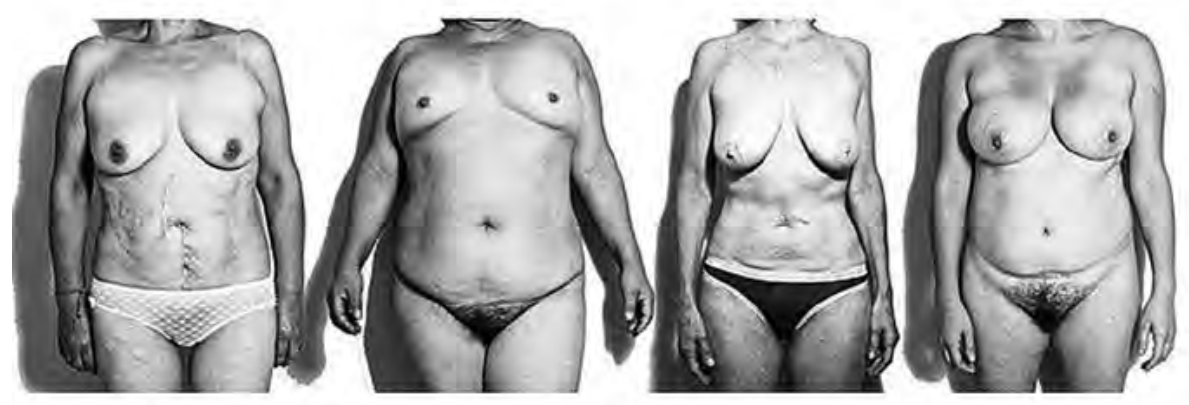

\section{f Campaña Todas somos migrantes}

La campaña "Todas somos migrantes" emerge en un contexto controvertido a nivel inter-estatal. Las presiones territoriales entre los Estados de Perú y Chile desembocaban en un juicio a nivel internacional que concedía derechos de soberanía al Estado de Perú sobre una porción marítimo-territorial que hace casi más de un siglo había estado sujeto a control del Estado chileno como trofeo de guerra: como patrimonio soberano. El virtual conflicto territorial mass mediatizado estratégicamente con el fin de espectacularmente plusvalorizar los conflictos racial-identitarios retorna a las y los migrantes a volver a interrogar los espectros del estado-nación que ha cedido a la red global por medio de la superposición de circulaciones transnacionales de capital que fácticamente desplazan a una cuestión de administración meramente formal

29 Extraído el 20 de julio del 2015 de:

http://www.interculturalidadypatrimonio.cl/campana-todos-somos-migrantes/ 
los confines geopolíticos modernos. Circulaciones trans-nacionales y g-locales que, como hemos rastreado, antes que preservar las antiguas líneas de demarcación soberanas están dispuestas para hacer proliferar nuevas fronteras en territorios antes no visiblemente conquistados y que hoy son capturados por una maquinaria extractiva imperial deslocalizada y dirigida a los cuerpos, los afectos, el deseo.

Frente a esta nueva reconfiguración del ejercicio de poder de las maquinarias gubernamentales transnacionales sobre el cuerpo se puede hablar en términos poscoloniales, y siguiendo a Segato, de una nueva economía de poder que opera antes que por una colonialidad del poder, como proceso de subjetivación y racialización de los $\operatorname{cuerpos}^{30}$, por una conquistualidad del poder, caracterizada menos por el ejercicio de diferenciación asimétrica de acuerdo a vectores de racialización, sexistas y generizados de poder, que por un desmantelamiento de las territorialidades políticas dirigida a la atenuación de las potencias inventivas, las afectividades implicantes y las capacidad de acción política de los cuerpos. Una conquistualidad que opera por medio de una sobresaturación de poder que asedia y usurpa las inclinaciones políticas estratégicas de las y los sujetos en la reivindicación de derechos en función de una exigencia global de acumulación y producción de capital.

Cuando propongo la noción de derecho me vuelvo a un problema filosófico político respecto a lo que Foucault ${ }^{31}$ propondrá como una experiencia de sí que se torna capaz de desbordar la economía de usos y valoraciones en las cuales el sujeto es contenido, normado y producido en función del reconocimiento de sí como unidad, como efecto de verdad, como práctica discursiva y como valoración social, puesta en entredicho por una relación intercambiaría del deseo.

En otros términos, un acercamiento experimental de nuevas pragmáticas de reconocimiento que abran brechas a los marcos sobresaturados de reconocibilidad por medio del despliegue de un ejercicio de derecho ciudadano que no se desliga de una acción ética y política, de nuevos modos de uso e intercambio incondicionados de los territorios, de las y los cuerpos, del deseo. Territorios que son compartidos de acuerdo a la intensificación de los deseos y las experiencias vitales entre las y los

30 QUIJANO, A, Colonialidad del Poder y Des/Colonialidad del Poder. Ponencia presentada en el XXVII Congreso De La Asociación Latinoamericana De Sociología, , Buenos Aires, 2009.

31 FOUCAULT, M, Historia de la sexualidad II: el uso de los placeres. XXI, Argentina, 2003. 
sujetos, territorios fronterizos en relación de acuerdo a la puesta en común de la experiencia de un impasse, de un malestar con las ficciones valorativas con que SE nos imponen circulaciones y unidades de medida, normas valorativas, como condición de legitimidad social.

En estos términos, el derecho sobre sí mismo, tiene que ver con la potencia de recrear las condiciones del reconocimiento en base a una experiencia compartida de desubjetivación, de impropiedad, de una experiencia común de fuga de la avanzada imperial neoliberal de conquistualidad de las circulaciones. Una experiencia común que destituya - inhabilite sus usos, sentidos y valoraciones - los sentidos epocales y las matrices de reconocibilidad con que SE nos obliga a transitar por la multiplicidad de simulacros ficcionales con los que SE reparte una prolija división sexual del trabajo, una peligrosamente sutil verticalidad y condicionalidad de las relaciones.

Desmontar el teatro del asedio con el cual se vela lo que Sassen señalará como la nueva geografía política global del capital, que atiende a la indistinción entre vida y trabajo, cuerpo y capital, en tiempos donde la consumación efectiva de una antropología política universal sólo pudo rentabilizar necropolíticamente la indistinción entre vida y política.

Retornar al cuerpo, y cartografiar sus fronteras, es también hacer un ejercicio de reconocimiento de las fronteras que lo fragmentan, que lo marcan, que lo constituyen y lo significan como vida vivida, como vida digna. "Todas Somos Migrantes" propuso una exposición del cuerpo, de sus pliegues, de sus cicatrices, de sus irreductibles contornos en función de afirmar la imposibilidad del modelaje estereotípico como condición de reconocimiento. El cuerpo, en la exposición del cuerpo de la mujer, nos retorna a la multiplicidad de fronteras por las cuales circulamos como experiencias irreductibles y excedentes de toda delimitación discursiva. "Todas Somos Migrantes" se planteó, así como un ejercicio cartográfico de la multiplicidad que somos, de las resistencias, fugas y devenires por los cuales transitamos junto a otras y otros afectos a nuevas rutas, habilitando corredores trans-fronterizos e indocumentados de viaje por en medio de la aldea global.

De alguna manera, el cuerpo de la mujer expuesto en sus transicionalidades supone una circulación del deseo que es inadmisible para la economía intercambiaría trans- 
nacional, porque no yace inscrito en un código semiótico neoliberal de reconocimiento sino en la experimentación sexual del territorio compartido, del cuerpo, del deseo, como red de agenciamientos maquínicos de exploración y fuga a una historia de forclusión, violencia, segregación, ocultamiento. En términos de Rossi Braidotti, podríamos decir que el recuadro fotográfico al infinito de Todas Somos Migrantes es la exposición incondicionada de las vidas al impasse entre la mujer y las mujeres, impasse que las constituye ${ }^{32}$, no solo en tanto mujer, sino en tanto masculinidades y feminidades atrofiadas en la capacidad de compartir nuevas experiencias sensibles del encuentro corpóreo, de un erotismo político, más allá o por en medio del régimen binario de género. La imagen sabotea en el ojo de la máquina dual heteronormativa, el recuadro lógico de la violencia y la asimetría.

La exposición del cuerpo de la mujer migrante no responde a un gesto de sustancialización de un sujeto femenino, sino a una táctica de anonimato como de diferencia, y que expone el cuerpo como territorialidad irreductible a cualquier forma de comunidad que se plantee como ficción unitaria — que se instala en las sociedades y en los sujetos desde la idea de patria, nación, estado y género- y que reproducen la derrota, la domesticación, la culpabilidad como condición de posibilidad para la socialización de nuestros cuerpos, como cuerpos expuestos y vulnerables a una identidad, a una economía del deseo y las circulaciones propias de una valoración neoliberal del cuerpo como mercancía intercambiable. En estos términos, se vuelca sobre la construcción de una superioridad moral. Deshabilita el Derecho de Concesión con que el intercambio se produce y preserva.

Al exponer fragmentos del cuerpo desiste del rostro para buscar desarticular la crueldad de la estratificación del marco diferencial del reconocimiento, planteándole a Levinas un desafío más allá de él para sensibilizar y erotizar las conexiones e interrupciones con la alteridad. Todas podían ser, ya que todas están tramadas por una cartografía afectiva capaz de modular el cuerpo y ponerlo en común como experiencia de viaje, como maleta con inquietantes saberes y sin miedo a cruzar entre fronteras, a correr los cercos, a traficar afectos.

La potencia del enunciado "Todas Somos Migrantes" nos permite reconocer de forma ambivalente la interseccionalidad de la opresión y en su reversibilidad las expe-

32 BRAIDOTTI, R. Sujetos Nómades. Argentina: Paidós, 2000. 
riencias autonómicas de resistencia y convergencia con que se desafía el malestar y el dolor. Ya no solo como una reivindicación al Estado de un poder y una determinada presencia en el mundo, sino también como una potencia afectiva e implicante que activa un diagrama estratégico frente a la economía general del poder, una necro-gubernamentalidad expansiva y una conquistualidad del poder trans-nacional, tornando sensible una condición general a la vez que diferencial de exposición a la violencia que nos constituye como sujetos de la época. Rossi Braidotti, en su texto Sujetos Nómades señala la necesidad de un proyecto político nómada que proponga una transicionalidad como estrategia política con respecto a la interseccionalidad de las violencias y las identidades. Un proyecto nómada para atravesar, deambular y derivar en la cartografía del poder neoliberal más allá de lo dispuesto.

El nómada en cuanto plantea al deseo como intensidad creativa, dispone las subjetivaciones al devenir mediante la construcción de prácticas desubjetivantes, máquinas de guerra, que puedan interrumpir las economías del deseo propiamente capitalistas, y junto con ello, los mecanismos con los que se internalizan los sentimientos de deuda y culpabilidad. En ese sentido, una teoría del género que afirme un proyecto político nómada debe apostar por localizarse activamente en las interseccionalidades capitalistas para desactivar en términos transcoloniales las representaciones parceladas con que se reproducen prácticas sistemáticas de violencia sobre los cuerpos. Coincido con Braidotti, que una teoría de género tiene que afirmar los hiatos, y radicalizar dicha afirmación con prácticas que permitan okuparlos, habitarlos, como zonas de experimentación de nuevas lenguas.

En estas circunstancias, desde Todas Somos Migrantes propongo un devenir migrante, que asumo con Braidotti no puede encaminarse si no es desde las asimetrías, desde las experiencias radicalmente singulares que a la vez que nos distancian, politizan el desafío de la proximidad como capacidad de interrupción de las diferencias sexuadas, de sus (dis)posicionamientos en la interseccionalidad en que opera lo masculino y lo femenino como valor y sentido epocal — como división sexual del trabajo como división sexual de la vida por el capital — señalando con esto que, en sus diferencias, la maquinaria abstracta capitalista produciría lo femenino y lo masculino asimétricamente, plusvalorizando hiatos e indiferencias, feminizando hombres, masculinizando mujeres, complejizando el vínculo apasionado del poder con que asegura mantener atrofiadas y reguladas las zonas de interconexión afec- 
tiva entre experiencias minoritarias donde convergen precarias, mujeres, migrantes, trabajadores, disidencias sexuales, disidencias existenciales. Por ello, el devenir mujer, trasladado a un devenir migrante por medio del enunciado "Todas Somos Migrantes", antes que afirmar el hiato de las diferencias sexuadas sería un clinamen, una trayectoria ingobernable con respecto al hiato y a la gestión capitalista del mismo. Creo pertinente pensar en un devenir migrante, parafraseando a Guattari, que nos vuelva necesario entender que en estos tiempos los problemas de las precarizadas mujeres no son directamente comparables a la de los precarizados hombres, sin embargo, tal vez, podamos considerar que tanto uno como otro participan del mismo tipo de crisis general que atraviesa a todas las sociedades del planeta en el momento actual ${ }^{33}$.

33 GUATTARI, F, ROLNIK, S. Micropolítica. Cartografías del deseo. Argentina: Tinta Limón, 2013. 


\section{Bibliografía}

Agamben, Giorgio. Homo Sacer II [en línea] extraído en 2016 de https://artilleriainmanente.noblogs.org/post/2017/01/14/stasis/, 2016

Arendt, Hanna. The Crisis in Education, de Between Past and Future (1959). Londres: Penguin Books, 1977

Butler, Judith. Marcos de Guerra. México: Paidós, 2010 ¿Quién le canta al Estado-nación? Lenguaje, política, pertenencia. Argentina: Paidós, 2009

. Mecanismos psíquicos de poder. España: Cátedra, 2001

Braidotti, Rossi. Sujetos Nómades. Argentina: Paidós, 2000

Foucault, Michel. Historia de la sexualidad II: el uso de los placeres. Argentina: XXI, 2003

Guattari, Félix, Rolnik, Suely. Micropolítica. Cartografías del deseo. Argentina: Tinta Limón, 2013

Mam, Movimiento Acción Migrante. Acerca de la amnistía migratoria en Chile [Disponible en web] http://www.revistasur.cl/revistasur.cl/2014/09/acerca-de-la-amnistia-migratoria-en-chile/, 2014

Noriega, Rodolfo. Sobre la amnistía migratoria, parte III. En Revista Sur [Disponible en web] http://www.revistasur.cl/revistasur.cl/2014/11/sobre-la-amnistia-migratoria-parte-iii/, 2014

SAssen, Saskia. Contrageografías de la globalización. Género y ciudadanía en los circuitos transfronterizos. Madrid: Traficantes de sueños, 2003

Segato, Rita. Pedagogía de la crueldad: entrevista a Rita Segato, [disponible en web] http://anarquiacoronada.blogspot.com/2015/05/pedagogia-de-la-crueldad-entrevista.html, 2015

Antropología y derechos humanos: alteridad y ética en el movimiento de los derechos universales. Brasilia: Serie antropológica, 2004

Stefoni, Carolina. Inmigrantes transnacionales: La Formación de comunidades y la transformación en ciudadanos (Capítulo 9). FLACSO, sede Chile [Disponible en web] http://bibliotecavirtual.clacso.org.ar/ar/libros/chile/flacso/artstef.pdf, 2004 - Transformaciones sociales a partir de los nuevos procesos migratorios. (Capítulo 1). En Generación de Diálogo Chile-Perú/Perú-Chile, Chile, 2014 
Rubin, GaYle. El tráfico de mujeres: notas sobre la "economía política" del sexo. En: Nueva Antropología. Vol. VIII, No 30, pp. 95 - 145, 1986

QuiJano, Aníbal. Colonialidad del Poder y Des/Colonialidad del Poder, Buenos Aires, Argentina: Ponencia presentada en el XXVII Congreso De La Asociación Latinoamericana De Sociología, 2009

Valencia, Sayak. Capitalismo Gore. Control económico, violencia y narcopoder. México: Paidós, 2016

\section{Informes}

Anuario (Departamento de Extranjería y Migración). Migración en Chile 2005-2014 [Disponible en web] http://www.extranjeria.gob.cl/media/2016/02/Anuario-Estad\% C3\%ADstico-Nacional-Migraci\%C3\%B3n-en-Chile-2005-2014.pdf, 2014

INDH - Instituto Nacional de Derechos Humanos. Informe Anual. Situación de los Derechos Humanos en Chile, Santiago de Chile, 2011

INE - Instituto Nacional de Estadística. Datos extraídos el 20 de julio de 2015 en www.ine.cl/filenews/files/2011/enero/pdf/enfoque_extranjeros.pdf, 2015

OBDMI - La migración en Chile: breve reporte y caracterización, Instituto Universitario de estudios sobre Migraciones, Madrid, España, 2016 